\title{
RELEVANCE OF OSTEOCLAST-SPECIFIC ENZYME ACTIVITIES IN CELL-BASED IN VITRO RESORPTION ASSAYS
}

\author{
A. Bernhardt*, K. Koperski, M. Schumacher and M. Gelinsky \\ Centre of Translational Bone, Joint and Soft Tissue Research, Technische Universitaet und Universitaetsklinikum \\ Dresden, Germany
}

\begin{abstract}
Cell-based in vitro resorption assays are an important tool to simulate the in vivo biodegradation of resorbable bone graft materials and to predict their clinical performance. The present study analyses the activity of osteoclastspecific enzymes as potential surrogate measures for classical pit assay, which is not applicable on irregular structured materials. Osteoclasts derived from human peripheral blood mononuclear cells were cultivated on different surfaces: calcium phosphate bone cements (CPC), dentin discs, osteoblast-derived extracellular matrix (ECM) and tissue culture polystyrene as control. Pit formation on the resorbable materials was investigated and correlated with the activity of tartrate resistant acid phosphatase (TRAP), carbonic anhydrase II (CAII) and cathepsin K (CTSK). Furthermore, the relation between intra- and extracellular enzyme activities was examined for TRAP and CTSK during resorption of the different materials. Resorbed area of CPC correlated with intracellular TRAP activity and intracellular CAII activity. Highest resorption was detected at around $\mathrm{pH}$ 7.2. Resorbed area on dentin correlated with the extracellular CTSK activity and extracellular TRAP activity and was maximal at around $\mathrm{pH}$ 6.8. Osteoclasts cultivated on cell-derived mineralised ECM showed a good correlation between both extracellular TRAP and CTSK activity and the release of calcium ions. Based on these data a different regulation of TRAP and CTSK secretion is hypothesised for the resorption of inorganic calcium phosphate compared to the resorption of collagenous mineralised matrix.
\end{abstract}

Keywords: Osteoclast, in vitro resorption, TRAP, carbonic anhydrase II, cathepsin K, pit assay, enzyme activity, calcium phosphate bone cement, dentin, mineralised collagen.

*Address for correspondence:

Anne Bernhardt

Fetscherstr. 42

01309 Dresden, Germany

Telephone number: +49 3514586692

Email: anne.bernhardt@tu-dresden.de

\section{Introduction}

Resorbable bone graft materials have become an important alternative to autologous bone tissue for regeneration of bone defects. After implantation, the balance between new bone formation and resorption of the materials is crucial for successful remodelling. Therefore, in vitro evaluation of new biomaterials requires not only examination of the interactions with osteoblasts or osteoblast precursors, but also the analysis of osteoclast-mediated degradation of the materials.

Cell-based resorption assays of biomaterials are widely performed using osteoclasts and osteoclast-like cell lines (Zhang et al., 2012). Typical parameters for the estimation of osteoclastic resorption involve the number of multinucleated cells which stain positive for tartrate-resistant acid phosphatase (TRAP), the area and volume of resorption pits and the number of actin rings. Intriguing microscopic methods, such as super depth surface profile measurement microscopy (Soysa et al., 2009), infinite focus microscopy (Winkler et al., 2010) and stereo scanning electron microscopy (Detsch et al., 2010; Hefti et al., 2010) have been applied beside confocal laser scanning microscopy and atomic force microscopy for the accurate volumetric analysis of osteoclastic resorption. However, the quantification of resorption pits requires planar substrates with relatively smooth surfaces (roughness below $1 \mu \mathrm{m}$ ) (Zhang et al., 2012) to discriminate between resorption pits and irregularities of the biomaterial. Pit formation assays are therefore not applicable for most bone graft materials comprising porous 3D structure or at least irregular surfaces. Furthermore, the application of microscopic methods to study resorption is time-consuming and limited to very small samples in order to obtain reliable quantitative data.

Detailed examination of osteoclast differentiation and development on biomaterials involves gene expression analysis of osteoclast markers such as TRAP, calcitonin receptor, cathepsin K and matrix metalloprotease-9 (MMP9), quantification of the activity of the osteoclast-specific enzymes TRAP and carbonic anhydrase II (CAII) and the quantification of bone matrix degradation products $\mathrm{Ca}^{2+}$ (Grossardt et al., 2010; Long et al., 2012; Montazerolghaem et al., 2015; Neutzsky-Wulff et al., 2010; Reichert et al., 2013) and collagen-derived peptides (Christgau et al., 1998; Neutzsky-Wulff et al., 2010; Rissanen et al., 2008). TRAP has long been established as a marker for osteoclast function (Minkin, 1982). Its activity is elevated in the serum of patients with bone diseases (Halleen et al., 2001) and it was demonstrated in vitro that the amount of secreted TRAP significantly correlated with the number of osteoclasts formed both on tissue culture polystyrene 
(TCPS) (Alatalo et al., 2000) and bone slices (Rissanen et al., 2008). Furthermore, it was shown that in vitro, resorption of osteoclasts isolated from TRAP knockout mice, was reduced by 26 \% (Hayman and Cox, 2003). Nevertheless, it was suggested many years ago that the secretion of TRAP might be independent of the resorption activity (Halleen et al., 2006). In addition, TRAP activity has been observed not only in multinucleated osteoclasts, but also in mononucleated round and spindle-shaped cells derived from osteoclast precursors (Glenske et al., 2014). Beside TRAP, which is proposed to finalise the degradation of organic bone matrix by reactive oxygen species and which is secreted together with the degradation products (Halleen et al., 1999), further osteoclast-specific enzymes are involved in osteoclastic resorption. CAII is responsible for the generation of protons in mature osteoclasts and cathepsin K (CTSK) is a very selective protease capable of cleaving collagen at several sites within the triple helix (Novinec and Lenarčič, 2013) and, therefore, a key player in osteoclastic matrix resorption. While TRAP activity has been quantified in numerous in vitro studies on osteoclast formation and differentiation, there are only few reports on the quantification of CAII activity for the evaluation of osteoclast function (Bernhardt et al., 2015; Detsch et al., 2010; Detsch et al., 2011) and CTSK activity has not yet been quantified to study osteoclastic resorption of biomaterials.

The focus of the present study was to explore possible correlations between the activity of osteoclast-specific enzymes TRAP, CAII and CTSK and the resorbed area of different biomaterial surfaces. The experimental setup included the differentiation of primary osteoclasts, derived from human mononuclear cells on dentin, calcium phosphate bone cement and osteoblast-derived extracellular matrix. Resorption was quantified by pit assay and the resorbed area was correlated with the intra- and extracellular activity of TRAP, CAII and CTSK. We aimed to identify parameters reflecting the osteoclastic resorption in biomaterials with irregular structure for future resorption studies.

\section{Materials and Methods}

\section{Resorbable materials}

Dentin slices were prepared from canine teeth of minipigs. Teeth were sawed into discs of $0.8 \mathrm{~mm}$ thickness using an electric diamond saw.

For CPC discs an $\alpha$-tricalcium phosphate based precursor powder (InnoTERE, Radebeul, Germany) was used. Upon mixing with aqueous solution using a liquid to powder ratio of $500 \mu \mathrm{l} / \mathrm{g}$, the cement formed a mouldable paste that set into $\mathrm{Ca}$-deficient, carbonated hydroxyapatite. Samples for in vitro experiments were prepared as discs of $6 \mathrm{~mm}$ diameter and $1 \mathrm{~mm}$ height using silicone moulds and allowed to set for $4 \mathrm{~d}$ in a water-saturated atmosphere at $37^{\circ} \mathrm{C}$ (Schumacher et al., 2013). Dentin and CPC discs were sterilised by $\gamma$-irradiation ( $25 \mathrm{kGy}$ ) prior to use in cell culture.

Osteoblast-derived native extracellular matrix was prepared as published by Lutter et al. (2010). Instead of
SaOS-2 cell line, primary human osteoblasts were used, which were isolated from spongious bone of human femoral heads of osteoarthritic patients undergoing total hip replacement at the University Hospital Carl Gustav Carus Dresden after informed consent (approval by the ethics commission of TU Dresden). Cells at passage 3 were seeded in 48 -well TCPS $\left(1 \times 10^{4}\right.$ cells/well $)$. After one week of cultivation in $\alpha$-MEM containing $10 \% \mathrm{FCS}$, $100 \mathrm{U} / \mathrm{mL}$ penicillin, $100 \mu \mathrm{g} / \mathrm{mL}$ streptomycin and $2 \mathrm{mM}$ glutamine, the medium was further supplemented with $10^{-7} \mathrm{M}$ dexamethasone, $5 \mathrm{mM} \beta$-glycerophosphate and $12.5 \mu \mathrm{g} / \mathrm{mL}$ ascorbic acid-2 phosphate (all from SigmaAldrich, Taufkirchen, Germany). Cells were cultivated for 4 weeks until a closed layer of mineralised extracellular matrix was formed in the dishes. Cells were removed by addition of $15 \mathrm{mM}$ ammonium hydroxide solution and washed three times with PBS.

\section{Isolation of PBMC and osteoclastogenic differentiation on different materials}

PBMC were isolated from human buffy coats as described previously (protocol YELLOW, Bernhardt et al., 2015). Briefly, PBMC were separated by density gradient centrifugation (Ficoll Paque Plus, $1000 \times g$ ) and remaining erythrocytes were lysed with deionised water for $1 \mathrm{~min}$. Monocyte content (cells with 7.6-12 $\mu$ m diameter) of the cell suspension was quantified by an automated cell counter (Scepter, Merck Millipore, Darmstadt, Germany). For seeding, cells were resuspended in $\alpha$-MEM (Gibco, supplied by Fisher Scientific, Schwerte, Germany) containing $10 \%$ heat-inactivated FCS, $100 \mathrm{U} / \mathrm{mL}$ penicillin, $100 \mu \mathrm{g} / \mathrm{mL}$ streptomycin and $2 \mathrm{mM}$ glutamine. 96-well polystyrene cell culture plates were seeded with PBMC containing $1 \times 10^{5}$ monocytes and CPC discs with PBMC containing $2 \times 10^{5}$ monocytes, both in $200 \mu \mathrm{L}$ medium per sample. Dentin slices and ECM were seeded in 48-well polystyrene cell culture plates with PBMC containing $4 \times 10^{5}$ monocytes in $400 \mu \mathrm{L}$ medium per sample. On the next day, samples were divided into four groups and four different modifications of $\alpha$-MEM were used as basal medium, further supplemented with $5 \%$ heat-inactivated FCS, $5 \%$ human A/B serum (SigmaAldrich), $100 \mathrm{U} / \mathrm{mL}$ penicillin, $100 \mu \mathrm{g} / \mathrm{mL}$ streptomycin, $2 \mathrm{mM}$ glutamine and $25 \mathrm{ng} / \mathrm{mL} \mathrm{M-CSF}$ (Peprotech, Hamburg, Germany). The different modifications of $\alpha$-MEM were as follows: 1$)$ normal liquid $\alpha$-MEM without nucleosides (Gibco), 2) powdered $\alpha$-MEM without nucleosides (Gibco), reconstituted in water and supplemented with $2.2 \mathrm{~g} / \mathrm{L}$ sodium hydrogen carbonate, 3) medium supplemented with $1 \mathrm{~g} / \mathrm{L}$ sodium hydrogen carbonate, 4) medium supplemented with $0.5 \mathrm{~g} / \mathrm{L}$ sodium hydrogen carbonate. After two days of cultivation, cells were additionally supplemented with $50 \mathrm{ng} / \mathrm{mL}$ RANKL (Peprotech). Medium was changed twice weekly. During medium change the $\mathrm{pH}$ of selected samples was checked (one sample per condition, donor, material and $\mathrm{pH}$ ) with a handheld $\mathrm{pH}$ meter (pHSpear, Eutech, supplied by Fisher Scientific, Schwerte, Germany). Due to the loss of $\mathrm{CO}_{2}$ outside the incubator, the $\mathrm{pH}$ measurement was not possible in all samples. After $16 \mathrm{~d}$ of cultivation, cell culture supernatants were frozen at $-20{ }^{\circ} \mathrm{C}$ and the 
cell-seeded materials were washed with PBS and frozen at $-80{ }^{\circ} \mathrm{C}$ until further analysis. Prior to determination of intracellular enzyme activities samples were thawed, cells were lysed using $1 \%$ Triton X-100 in PBS for 50 min on ice with a 10 min treatment in an ultrasonic bath. Cell lysates were collected in $0.5 \mathrm{~mL}$ tubes and subjected to the different assays. For TRAP staining, confocal laser scanning microscopy (cLSM) and von Kossa staining, cellseeded samples were fixed with $4 \%$ formaldehyde in PBS.

\section{TRAP Staining}

TRAP staining was performed for $10 \mathrm{~min}$ at $37^{\circ} \mathrm{C}$ by immersion of fixed samples in $0.3 \mathrm{mg} / \mathrm{mL}$ Fast Red Violet LB (Sigma) in $0.05 \mathrm{M}$ sodium acetate (Sigma), $0.05 \mathrm{M}$ acetic acid (Sigma), $0.03 \mathrm{M}$ sodium tartrate (Carl Roth, Karlsruhe, Germany), $0.1 \mathrm{mg} / \mathrm{mL}$ naphthol AS-MX phosphate disodium salt (Sigma) and $0.1 \%$ Triton X-100 (Sigma). After washing with PBS, cell nuclei were stained for 10 min using Mayer's Haemalum solution (AppliChem, Darmstadt, Germany) followed by rinsing in tap water. Stained samples were imaged using a Biorevo BZ-9000 (Keyence, Neu-Isenburg, Germany).

\section{Fluorescence microscopy}

For fluorescence staining, fixed cells were permeabilised with $0.2 \%$ Triton X-100 in PBS and autofluorescence was blocked with $3 \%$ BSA in PBS. Staining of cell nuclei and actin cytoskeleton was done using $20 \mathrm{ng} / \mathrm{mL}$ DAPI (4',6-diamidin-2-phenylindol, Invitrogen) and $25 \mu \mathrm{L} /$ $\mathrm{mL}$ AlexaFluor $4888^{\circledR}$ phalloidin (Invitrogen, supplied by Fisher Scientific, Schwerte, Germany), in $3 \%$ BSA in PBS. Samples were imaged using confocal laser scanning microscopy (LSM 510 Zeiss, Oberkochen, Germany), located in the core facility cellular imaging (CFCI) of the Medical Faculty of the Technical University Dresden.

\section{Quantification of TRAP activity}

Cell lysates and cell culture supernatants, both $10 \mu \mathrm{L}$, were mixed with TRAP reaction buffer [ $50 \mu \mathrm{L}$, composed of $2.5 \mathrm{mM}$ naphthol-ASBI-phosphate disodium salt hydrate (Sigma-Aldrich) in $100 \mathrm{mM}$ sodium acetate and $50 \mathrm{mM}$ disodium tartrate $\mathrm{pH}$ 6.1] and incubated at $37^{\circ} \mathrm{C}$ for $30 \mathrm{~min}$. Finally, $0.1 \mathrm{M} \mathrm{NaOH}(150 \mu \mathrm{L})$ was added to stop the enzymatic reaction. The intensity of fluorescence was measured with a multifunction microplate reader at an excitation and emission wavelength of 405/520 nm. Calibration solutions, with different TRAP concentrations (0.6 to $12 \mathrm{U} / \mathrm{L}$ ) taken from a commercially available ELISA kit (BoneTRAP, Medac, Germany), were used to correlate the fluorescence intensity with TRAP activity.

\section{Quantification of CAII activity}

CAII was quantified based on its esterase activity (Innocenti et al., 2008). Cell lysates (50 $\mu$ l) were mixed with CAII reaction buffer containing $12.5 \mathrm{mM}$ TRIS $\mathrm{pH}$ 7.5, $75 \mathrm{mM} \mathrm{NaCl}$ and $2 \mathrm{mM}$ 4-nitrophenylacetate (50 $\mu \mathrm{L}$, Sigma). Absorbance was monitored at $400 \mathrm{~nm}$ for 5 min. Conversion to 4-nitrophenol was calculated from the slope of the absorbance plot using a calibration line from different dilutions of $1 \mathrm{mM} 4$-nitrophenol (Sigma).
Determination of CAII activity in cell culture supernatants was not possible because of the high background activity.

\section{Quantification of CTSK activity}

A $10 \mathrm{mM}$ stock solution of Z-LR-AMC (Enzo Life Sciences, Lörrach, Germany) was prepared in DMSO. For the substrate working solution the stock solution was dissolved 1:100 in 0.1 M sodium acetate buffer containing $4 \mathrm{mM}$ EDTA and $4 \mathrm{mM}$ DTT at $\mathrm{pH}$ 5.5. $10 \mu \mathrm{L}$ of cell lysate or $20 \mu \mathrm{L}$ of cell culture supernatant were mixed with lysis buffer or cell culture medium, respectively to a final volume of $50 \mu \mathrm{L}$. After addition of $50 \mu \mathrm{L}$ of substrate working solution the plate was incubated for $30 \mathrm{~min}$ at $37^{\circ} \mathrm{C}$ and then subjected to fluorescence measurement at an excitation/emission wavelength of $365 / 440 \mathrm{~nm}$. The amount of released aminomethylcoumarin (AMCA) was quantified with a calibration line. Cell culture medium and lysis buffer as well as materials incubated in cell culture medium without cells were used as blanks.

\section{Analysis of resorption pits on CPC and dentin}

After performing cell lysis for biochemical measurements, CPC and dentin samples were washed with deionised water and dried at $60{ }^{\circ} \mathrm{C}$ for $12 \mathrm{~h}$. After drying, samples were mounted on stubs, sputter coated with carbon and imaged using a Philips XL 30/ESEM with FEG (field emission gun), operated in scanning electron microscopy (SEM) mode at $10 \mathrm{~mm}$ working distance and $6 \mathrm{kV}$ using a SE detector. Six independent SEM images per sample with $500 \times$ magnification were used for the calculation of resorption area applying the open source software Fiji (Schindelin et al., 2012). The combined area of resorption pits and trails was calculated after manually marking with the oval selection tool.

\section{$\mathrm{Ca}^{2+}$ quantification in the cell culture medium}

$\mathrm{Ca}^{2+}$ content in the cell culture medium of osteoclasts on cell-derived ECM was determined using a colorimetric test (Fluitest Ca CPC, Analytikon, Lichtenfels, Germany) applying the o-cresolphthalein complex method. $\mathrm{Ca}^{2+}$ concentration of the samples was calculated from a calibration line prepared with $\mathrm{CaCl}_{2}$ and $\mathrm{Ca}^{2+}$ concentration of the medium incubated with cell-derived ECM without osteoclasts was subtracted from the $\mathrm{Ca}^{2+}$ of the respective cell-seeded samples.

\section{Von Kossa staining for resorption of ECM}

Staining of fixed samples was performed with $5 \% \mathrm{AgNO}_{3}$ for 30 min under exposure to light, followed by fixation with $5 \%$ sodium thiosulphate. Samples were imaged with a Leica stereomicroscope. Resorbed area was calculated applying the open source software Fiji (Schindelin et al., 2012) using the threshold function. Three samples were imaged for each condition.

\section{Statistics}

Pearson correlations were calculated between the values of pit area (only for resorbable substrates), intracellular TRAP activity (TRAP L), extracellular TRAP activity (TRAP 

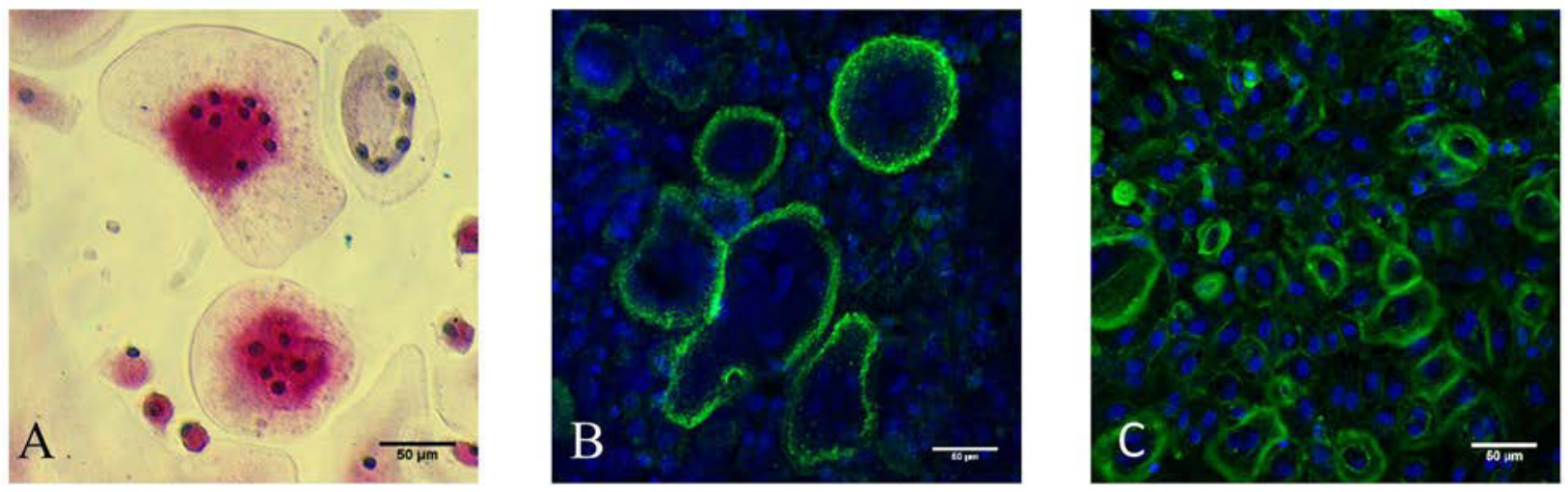

Fig. 1. Representative images of osteoclast formation on different surfaces after $14 \mathrm{~d}$ of stimulation with $\mathrm{M-CSF} /$ RANKL. (A) TCPS light microscopic image staining of TRAP activity (red), counterstaining of nuclei (blue) with haematoxylin. (B) Dentin (C) CPC confocal laser scanning microscopy images. Cytoskeleton appears in green after staining with Alexa Fluor 488 phalloidin and nuclei appear blue after staining with DAPI.

S), intracellular CTSK activity (CTSK L), extracellular CTSK activity (CTSK S) and CAII activity (using Origin 9.1 software, OriginLab). For TCPS 144 pairs of value originating from cells of 9 donors were included into the calculation. For osteoblast-derived ECM 72 pairs of values originating from cells of 6 donors were included. For dentin discs, 48 pairs of values from 6 donors and for CPC 24 pairs of values (average values from 2 samples each) originating from cells of 6 donors were included.

Two way analysis of variance (ANOVA) with $\mathrm{pH}$ and cell donor as independent parameters was used to evaluate statistical significance at $p<0.05$. Post hoc analysis was performed to determine multiple comparisons using the Tukey method (Origin 9.1 software, OriginLab).

\section{Results}

\section{Osteoclast differentiation}

PBMC of different donors were successfully differentiated into multinucleated osteoclasts on the examined surfaces. Osteoclast formation on TCPS started 2-3 d after first supplementation of medium with RANKL. After $14 \mathrm{~d}$ of supplementation with RANKL, multinucleated TRAP positive cells were imaged on TCPS and extracellular bone matrix. For the opaque substrates, dentin and CPC, multinucleated cells with actin rings were visualised by fluorescence staining after $14 \mathrm{~d}$ of osteoclastic stimulation (Fig.1).

\section{Correlation between TRAP staining and osteoclast enzyme activities on non-resorbable TCPS}

PBMC, from 9 independent donors, were differentiated into osteoclasts on TCPS. TRAP positive multinucleated cells were detected in all samples after 7 and $14 \mathrm{~d}$ of differentiation, but size and amount were strongly donordependent. However, under standard conditions ( $\mathrm{pH} 7.4$ ) the quantified TRAP activity in cell culture lysate seems to correspond to the TRAP staining.

Osteoclast cultures in media with different sodium hydrogen carbonate content resulted in $\mathrm{pH}$ values of approximately 7.4, 7.2, 7.0 and 6.8, respectively. Different amounts of TRAP positive multinucleated cells were detected at different $\mathrm{pH}$. Most TRAP positive multinucleated cells were commonly detected between $\mathrm{pH}$ 7.2 and 7.0, but their number and size differed between cells of different donors (Fig. 2A, G).

At the lowest examined $\mathrm{pH}$ (around 6.8), only a few osteoclasts were observed. Osteoclastic enzyme activities were determined both in the cell culture supernatants after $14 \mathrm{~d}$ of osteoclastic stimulation and in the cell lysates at the same time point. Up to $42 \%$ of the TRAP activity was secreted, the ratio of intracellular to extracellular TRAP varied with the donor and highest percentage of secreted TRAP was detected at pH 7.0. Nevertheless, the variations were not large and a significant linear correlation between extra- and intracellular TRAP activity ( $r=0.84104)$ was found when comparing all pairs of values. Lowest TRAP activities were detected at pH 6.8 (Fig. 2B, C, H, I), which corresponds to the results of TRAP staining (Fig. 2A, G). CAII activities did not show such large variations, both when comparing different donors and different $\mathrm{pH}$. Lowest values were likewise detected at pH 6.8 (Fig. 2F, L). However, there was no significant linear correlation between TRAP activities (extra- and intracellularly) and CAII activity. CTSK activities were detected both extra- and intracellularly. The ratio between intra- and extracellular activity showed very high variations. The secreted enzyme activity varied between 0.8 and $90 \%$, whereas the extracellular CTSK activity (CTSKS) often exceeded the intracellular activity (CTSK L). The variations in CTSK activity were mainly donor dependent, but we also realised a trend towards higher extracellular CTSK activity between pH 7.2 and 7.0. Consequently, there was no significant correlation between extra- and intracellular CTSK activity when calculated for all donors, at all examined $\mathrm{pH}$ conditions. For osteoclasts on TCPS the extracellular CTSK activity (Fig. 2E, K) seems to correlate better with the TRAP staining (Fig. 2A, G) than intracellular CTSK activity (Fig. 2D, J). 


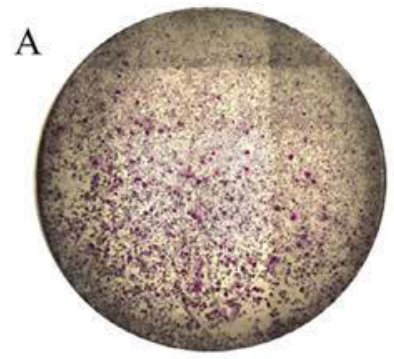

pH 7.4

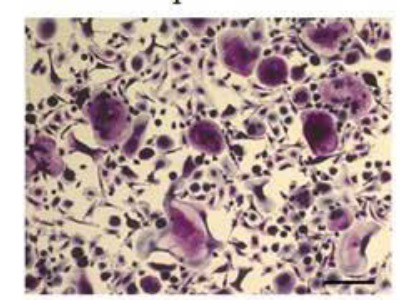

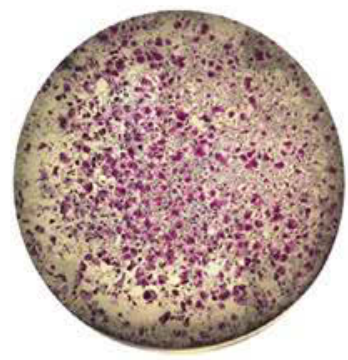

$\mathrm{pH} 7.2$

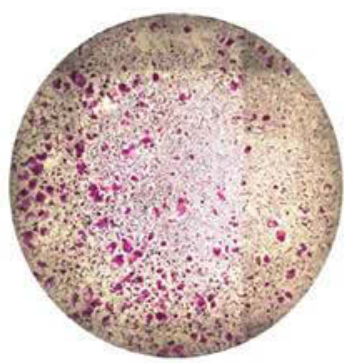

$\mathrm{pH} 7.0$

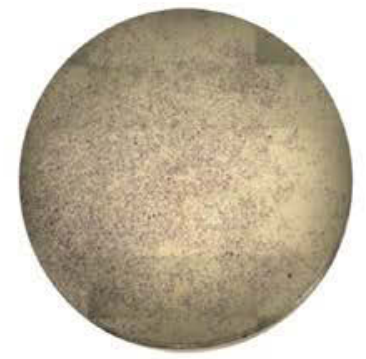

$\mathrm{pH} 6.8$
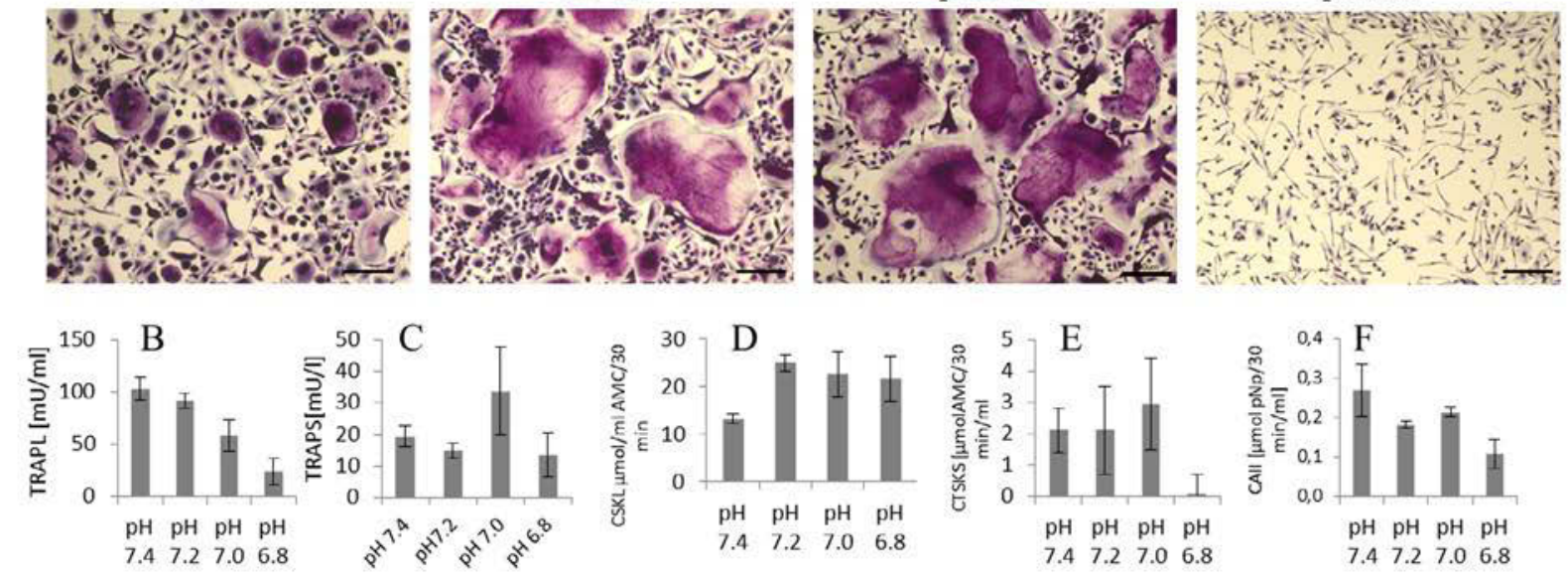

\section{G}

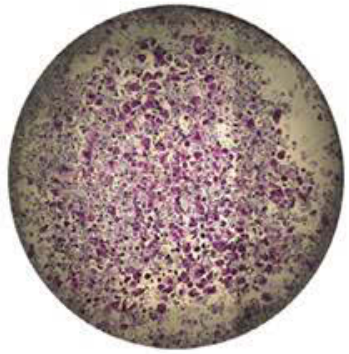

pH 7.4

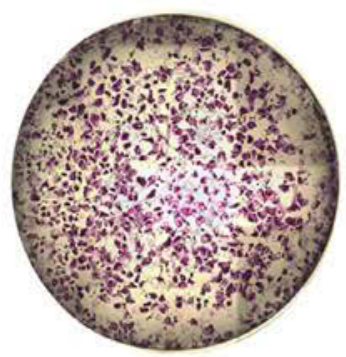

$\mathrm{pH} 7.2$
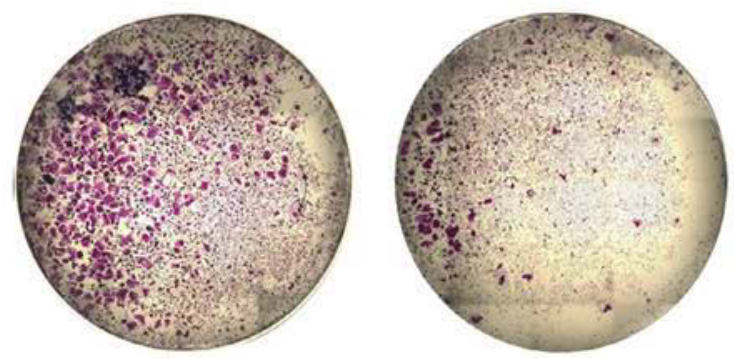

$\mathrm{pH} 7.0$

pH 6.8
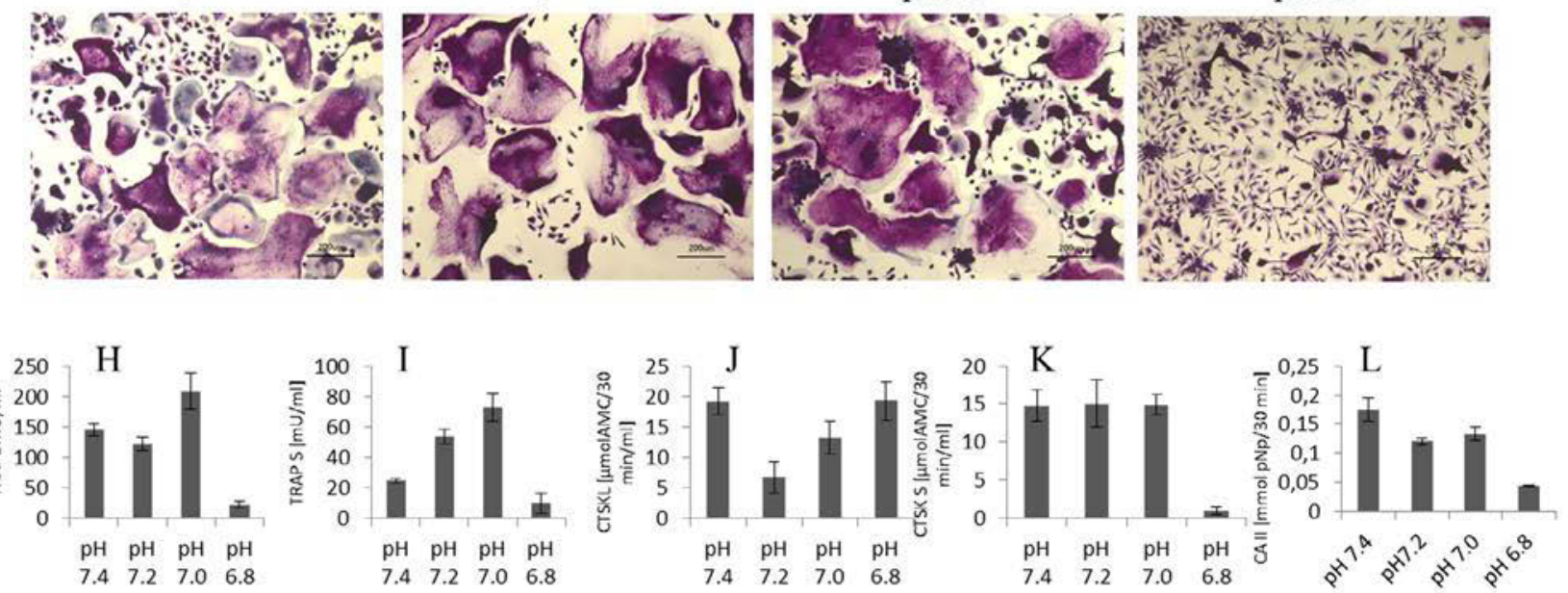

Fig. 2. Representative images of TRAP staining and enzyme activity data for osteoclasts derived from human PBMC after $14 \mathrm{~d}$ of osteoclastic stimulation. (A, G) TRAP staining after cultivation at different $\mathrm{pH}$ conditions. Upper line: overview over the whole 48-well sample; lower line: inserts with higher magnification; scale bar represents $200 \mu \mathrm{m}$. (B, H) TRAP activity from cell lysates (TRAPL); (C, I) TRAP activity from cell culture supernatant (TRAPS); (D, J) CTSK activity from cell lysates (CTSKL); (E, K) CTSK activity from cell culture supernatant (CTSKS); (F, L) CAII activity. (A-F) cells from donor II; (G-L) cell from donor VII. Enzyme activity data represent average of 5 individual samples \pm standard deviation. 
$\mathrm{pH} 7.2$

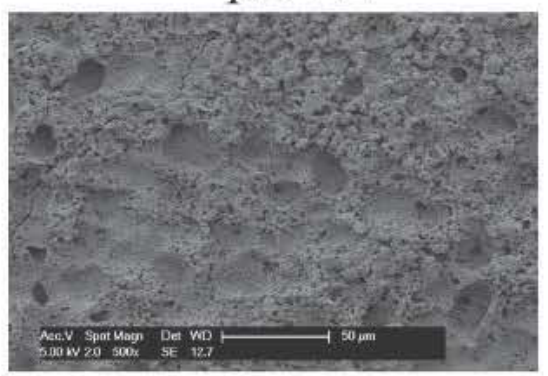

$\mathrm{pH} 6.6$

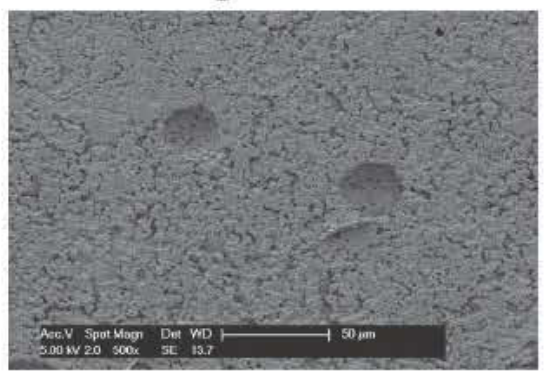

$\mathrm{pH} 7.0$

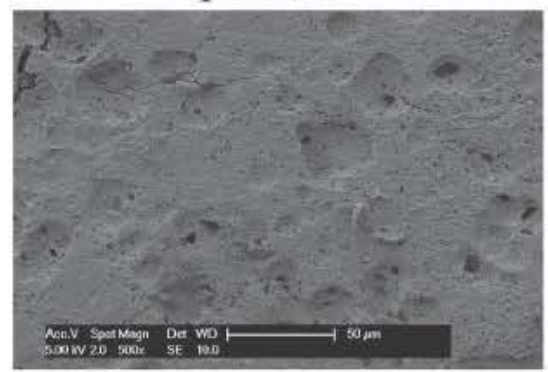

control

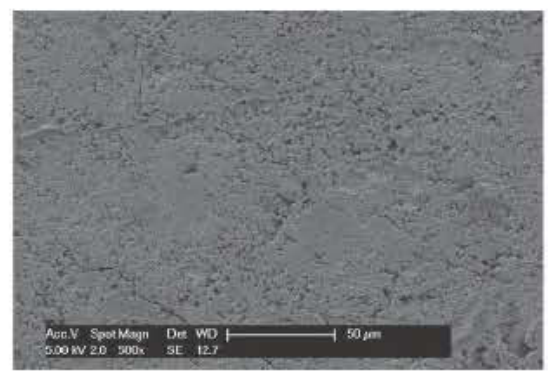

$\mathrm{pH} 6.8$

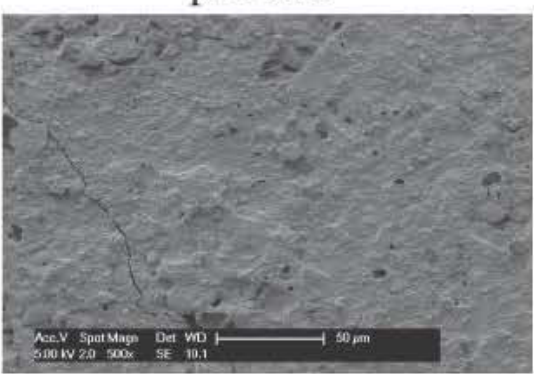

Fig. 3. Representative SEM images of CPC samples after osteoclastic resorption at different $\mathrm{pH}$ for $14 \mathrm{~d}$ and after removal of the cells. For control CPC samples were cultivated only with cell culture medium for $14 \mathrm{~d}$. Scale bars represent $50 \mu \mathrm{m}$.

Table 1. Linear correlation coefficients $r$ (Pearson) between pit area and different enzyme activities on $\mathrm{CPC},{ }^{*} p<0.05 ;{ }^{*} p<0.01 . \mathrm{L}=$ lysate, $\mathrm{S}=$ supernatant. Cells of six independent donors at four different $\mathrm{pH}$ conditions were included in this analysis.

\begin{tabular}{|l|l|l|l|l|l|}
\hline & TRAP L & TRAP S & CTSK L & CTSK S & CAII \\
\hline Pit area & $r=0.62017 * *$ & $r=0.34478$ & $r=0.30363$ & $r=0.3524$ & $r=0.49988 *$ \\
& $p=0.00123$ & $p=0.09895$ & $p=0.1492$ & $p=0.09124$ & $p=0.01287$ \\
\hline
\end{tabular}

\section{Resorption of calcium phosphate bone cements and correlation with osteoclast-specific enzymes}

Osteoclast cultures in media with different sodium hydrogen carbonate content, in the presence of CPC, resulted in $\mathrm{pH}$ values of 7.2, 7.0,6.8 and 6.6, respectively. After $14 \mathrm{~d}$ of osteoclastic stimulation, resorption pits were visible on the cement surface after removing the cells (Fig. 3). The number of pits decreased drastically with decreasing $\mathrm{pH}$ for the cells of all examined donors.

This decrease of resorption pits was reflected by decreased activity of TRAPL, CTSKL and CAII (Fig. 4). These intracellular enzyme activities were significantly decreased at $\mathrm{pH} 7.0$ and 6.6 compared to $\mathrm{pH} 7.2$. In contrast, significant correlations between resorbed area and activity were only found for TRAPL and CAII (Table 1). Furthermore, there was a significant correlation (0.81395) (Table 4) between extra- and intracellular TRAP activities. Percentage of secreted TRAP was between 4 and $17 \%$ and significantly highest values were detected at $\mathrm{pH}$ 6.6. Percentage of secreted CTSK was between 0 and $19 \%$ and variations were mainly donor-dependent.

\section{Resorption of dentin and correlation with osteoclast- specific enzymes}

Dentin slices are the gold standard for investigations on in vitro resorption due to their smooth surface and close composition to bone. Osteoclast-like multinucleated cells were observed after $14 \mathrm{~d}$ of osteoclastogenic stimulation. After removal of the cells, resorption pits were visible on the dentin surfaces using SEM. Osteoclasts cultured in media with different sodium hydrogen carbonate content in the presence of dentin, resulted in $\mathrm{pH}$ values of 7.4, 7.2, 7.0 and 6.8 , respectively. The largest resorbed area was detected at $\mathrm{pH} 6.8$ (Fig. 5). Furthermore, the pit diameter and depth increased with decreasing $\mathrm{pH}$. Calculated resorbed area was significantly higher at $\mathrm{pH} 6.8(p<0.05)$ compared to all other $\mathrm{pH}$ conditions (Fig. 6).

CAII activity, as well as intracellular TRAP activity, did not show significant differences between the $\mathrm{pH}$ conditions. In the case of TRAPL, this was possibly due to high variation between the donors. Intracellular CTSK activity was significantly increased at $\mathrm{pH} 7.2$ compared to all other $\mathrm{pH}$ conditions $(p<0.05)$, which does not reflect the resorption behaviour. Extracellular TRAP activity was significantly increased at $\mathrm{pH} 6.8$ and $\mathrm{pH} 7.0$ compared to $\mathrm{pH} 7.2$ and $\mathrm{pH} 7.4$, which partially reflects the resorption behaviour. Consequently a significant correlation between TRAP S and pit area was found (Table 2).

Percentage of secreted TRAP was between 3 and $55 \%$ with significantly highest secretion at $\mathrm{pH}$ 6.8. Similarly, extracellular CTSK activity reflected the resorption on dentin - since its activity was also significantly increased at $\mathrm{pH} 6.8$ compared to all other $\mathrm{pH}$ conditions. Furthermore, a good and significant correlation $(r=0.78193)$ was found between pit area and extracellular CTSK activity (Table 2). The percentage of extracellular CTSK ranged between 0.3 and $40 \%$ and significantly highest values were recorded at $\mathrm{pH}$ 6.8. Furthermore, a significant high correlation was calculated for CTSKS and TRAPS ( $r=0.90485)$. 

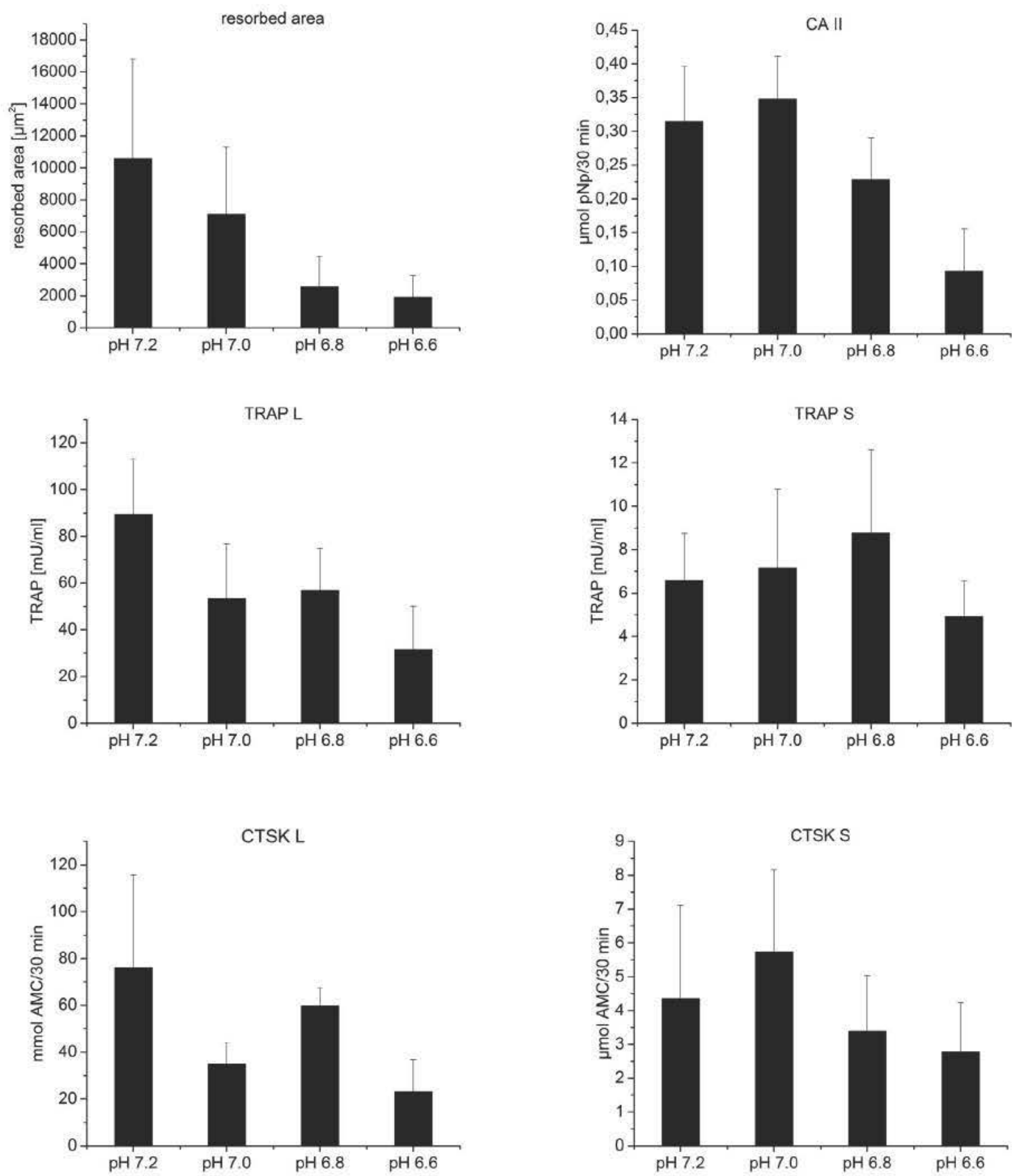

Fig. 4. Resorption of CPC. Resorption pit area and osteoclast related enzyme activities from cell culture supernatants (TRAP S, CTSK S) and lysates (TRAP L, CTSK L, CAII) after $14 \mathrm{~d}$ of PBMC cultivation with osteoclastic stimulation on CPC disks at different $\mathrm{pH}$. Data for cells of three donors (each $n=2)$ were averaged and shown \pm standard deviation. Two way ANOVA was performed with $\mathrm{pH}$ and donor as parameters. Significant differences $(p<0.05)$ were identified as follows. For TRAPL: $\mathrm{pH} 7.2$ vs. $\mathrm{pH} 7.0, \mathrm{pH} 6.8$ and $\mathrm{pH}$ 6.6. For CTSKL $\mathrm{pH} 7.2$ vs. $\mathrm{pH} 7.0$ and pH 6.6 as well as $\mathrm{pH} 6.8$ vs. $\mathrm{pH}$ 6.6. For CAII: $\mathrm{pH} 6.6$ vs. $\mathrm{pH} 7.2, \mathrm{pH} 7.0$ and $\mathrm{pH} 6.8$ as well as $\mathrm{pH} 6.8$ vs. $\mathrm{pH} 7.0$. Furthermore, significant differences $(p<0.05)$ between two of the three donors were detected for TRAP L activity.

Table 2. Linear correlation coefficients $\mathrm{r}$ (Pearson) between pit area and different enzyme activities on dentin, ${ }^{*} p<0.05 ;{ }^{* * *} p<0.001 . \mathrm{L}=$ lysate, $\mathrm{S}=$ supernatant, cells of six independent donors at four different $\mathrm{pH}$ conditions were included in this analysis.

\begin{tabular}{|l|l|l|l|l|l|}
\hline & TRAPL & TRAP S & CTSK L & CTSK S & CAII \\
\hline pit area & $r=0.31655^{*}$ & $r=0.64816^{* * *}$ & $r=-0.15466$ & $r=0.78193^{* * *}$ & $r=0.04784$ \\
& $p=0.02838$ & $p=6.33 \times 10^{-7}$ & $p=0.2939$ & $p=7.41 \times 10^{-11}$ & $p=0.74678$ \\
\hline
\end{tabular}


pH 7.4
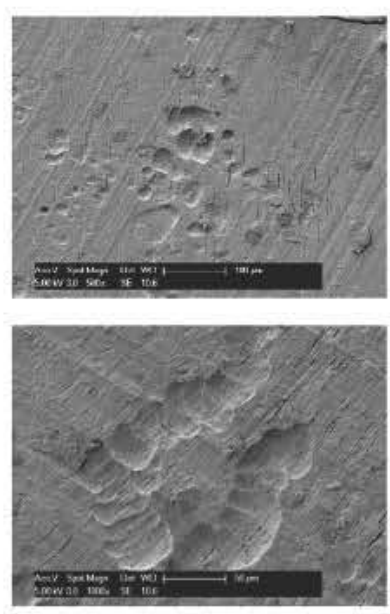

pH 7.2
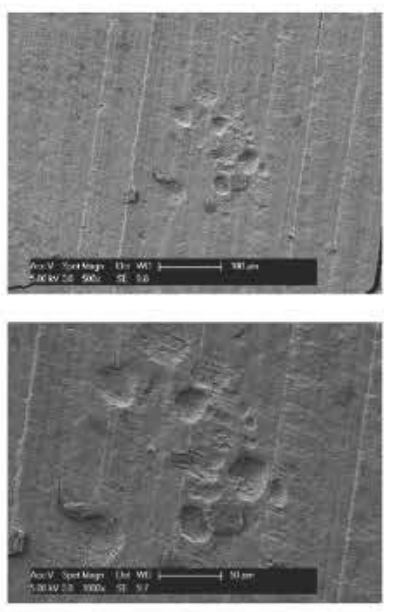

$\mathrm{pH} 7.0$
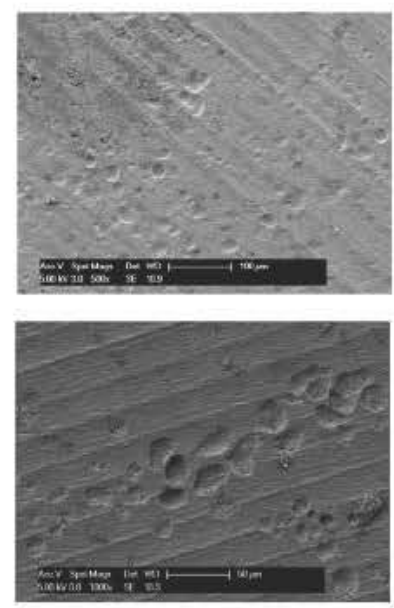

pH 6.8
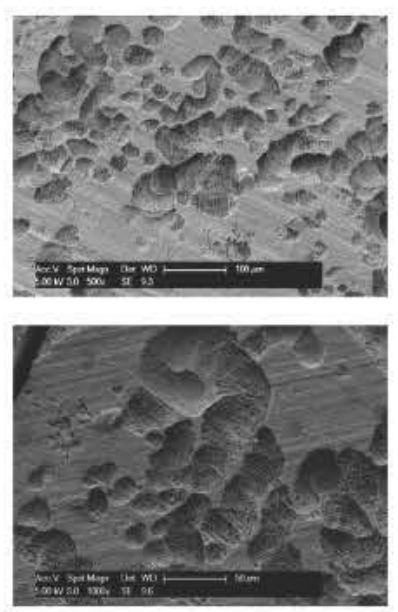

Fig. 5. Representative SEM images of dentin samples after osteoclastic resorption at different $\mathrm{pH}$ for $14 \mathrm{~d}$ and after removal of the cells. Scale bar represents $100 \mu \mathrm{m}$ (upper row) and $50 \mu \mathrm{m}$ (lower row).

Table 3. Linear correlations (Pearson) between resorbed area (RA) and extracellular osteoclast enzyme activities as well as $\mathrm{Ca}^{2+}$ release. Cells of six independent donors at four different $\mathrm{pH}$ conditions were included in the calculation. $* * p<0.01 ; * * p<0.001$.

\begin{tabular}{|l|l|l|l|l|l|l|}
\hline correlation & RA/CTSK & RA/TRAP & RA/Ca ${ }^{2+}$ & CTSK/TRAP & CTSK/Ca $^{2+}$ & $\mathbf{C a}^{2+} /$ TRAP \\
\hline$r$ & 0.1291 & $0.3816^{* *}$ & 0.3429 & $0.7450^{* * *}$ & $0.6963 * * *$ & $0.7293 * * *$ \\
$p$ & 0.2834 & 0.0010 & 0.0034 & $9.303 \times 10^{-14}$ & $1.56 \times 10^{-11}$ & $5.49 \times 10^{-13}$ \\
\hline
\end{tabular}

Table 4. Summary of the most relevant results.

\begin{tabular}{|c|c|c|c|c|c|c|c|c|c|}
\hline Surface & $\begin{array}{l}\text { Significant } \\
\text { correlations of } \\
\text { enzyme activity } \\
\text { and resorption }\end{array}$ & $\begin{array}{l}\text { Other } \\
\text { significant } \\
\text { correlations }\end{array}$ & $\begin{array}{l}\text { TRAPL } \\
(\mathrm{mU} / \mathrm{mL})\end{array}$ & $\begin{array}{l}\text { TRAPS } \\
(\mathrm{mU} / \mathrm{mL})\end{array}$ & \begin{tabular}{|l|} 
TRAP \\
secretion \\
$(\%)$
\end{tabular} & $\begin{array}{l}\text { CTSK L } \\
(\mu \mathrm{mol} \\
\mathrm{AMC} / \\
\mathrm{mL} / 30 \mathrm{~min})\end{array}$ & $\begin{array}{l}\text { CTSK S } \\
(\mu \mathrm{mol} \\
\mathrm{AMC} / \\
\mathrm{mL} / 30 \mathrm{~min})\end{array}$ & $\begin{array}{l}\text { CTSK } \\
\text { secretion } \\
(\%)\end{array}$ & $\begin{array}{l}\text { CA II } \\
(\mu \mathrm{mol} \\
\mathrm{pNp} / \\
\mathrm{mL} / 30 \mathrm{~min})\end{array}$ \\
\hline TCPS & non resorbable & $\begin{array}{l}\text { TRAPL/TRAPS } \\
r=0.6909\end{array}$ & $7.6-233$ & $0.18-156$ & $2-41$ & $4.5-98$ & $0-157$ & $0.8-90$ & $0.04-0.48$ \\
\hline$\overline{\mathrm{CPC}}$ & $\begin{array}{l}\text { pit area/TRAPL } \\
r=0.62017 \\
\text { pit area/CAII } \\
r=0.49988 \\
\end{array}$ & $\begin{array}{l}\text { TRAPL/TRAPS } \\
r=0.81395 \\
\text { TRAPL/CAII } \\
r=0.63592 \\
\end{array}$ & $3.8-112$ & $0.4-12$ & $4-17$ & $4.9-111$ & $0-8.3$ & $0-16$ & $0.05-0.4$ \\
\hline dentin & $\begin{array}{l}\text { pit area/CTSKS } \\
r=0.78193 \\
\text { pit area/TRAPS } \\
r=0.64816\end{array}$ & $\begin{array}{l}\text { CTSKS/TRAPS } \\
r=0.90485\end{array}$ & $14-184$ & $1.3-15$ & $3-55$ & $29-270$ & $0.12-32$ & $0.3-40$ & $0.12-0.8$ \\
\hline $\begin{array}{l}\text { native } \\
\text { bone } \\
\text { ECM }\end{array}$ & $\begin{array}{l}\text { no correlation } \\
\text { found }\end{array}$ & \begin{tabular}{l|} 
CTSKS $/ \mathrm{Ca}^{2+}$ \\
$r=0.6963$ \\
TRAPS/CTSKS \\
$r=0.7450$ \\
TRAPS $/ \mathrm{Ca}^{2+}$ \\
$r=0.7293$
\end{tabular} & $\begin{array}{l}\text { not } \\
\text { analysed }\end{array}$ & $2.5-113$ & - & $\begin{array}{l}\text { not } \\
\text { analysed }\end{array}$ & $0.6-19$ & - & \begin{tabular}{|l|} 
not \\
analysed
\end{tabular} \\
\hline
\end{tabular}

Resorption of osteoblast-derived extracellular bone matrix and correlation to osteoclast enzyme activities After $14 \mathrm{~d}$ of cultivation, native bone ECM was resorbed by the osteoclasts to a different extend, depending on the $\mathrm{pH}$. Resorbed areas were visible after von Kossa staining of the remaining mineralised ECM (Fig. 7). Samples, which were cultivated at $\mathrm{pH} 6.8$ displayed a significantly lower resorbed area compared to the other three $\mathrm{pH}$ conditions (Fig. 8). Besides osteoclastic enzyme activities, the $\mathrm{Ca}^{2+}$ concentration in the cell culture supernatant was also quantified. In all samples, $\mathrm{Ca}^{2+}$ concentration was above the basal $\mathrm{Ca}^{2+}$ level. Lowest $\mathrm{Ca}^{2+}$ concentrations were detected for samples which were cultivated at $\mathrm{pH} 6.8$.

In contrast to the resorbed area, which was in a similar range at $\mathrm{pH} 7.4,7.2$ and 7.0, extracellular TRAP and CTSK activities showed a peak at $\mathrm{pH}$ 7.0. At this condition, the enzyme activities were significantly higher compared to the other three $\mathrm{pH}$ conditions. The same results were obtained for $\mathrm{Ca}^{2+}$ release. Consequently, there were no significant correlations between resorbed area and CTSK 

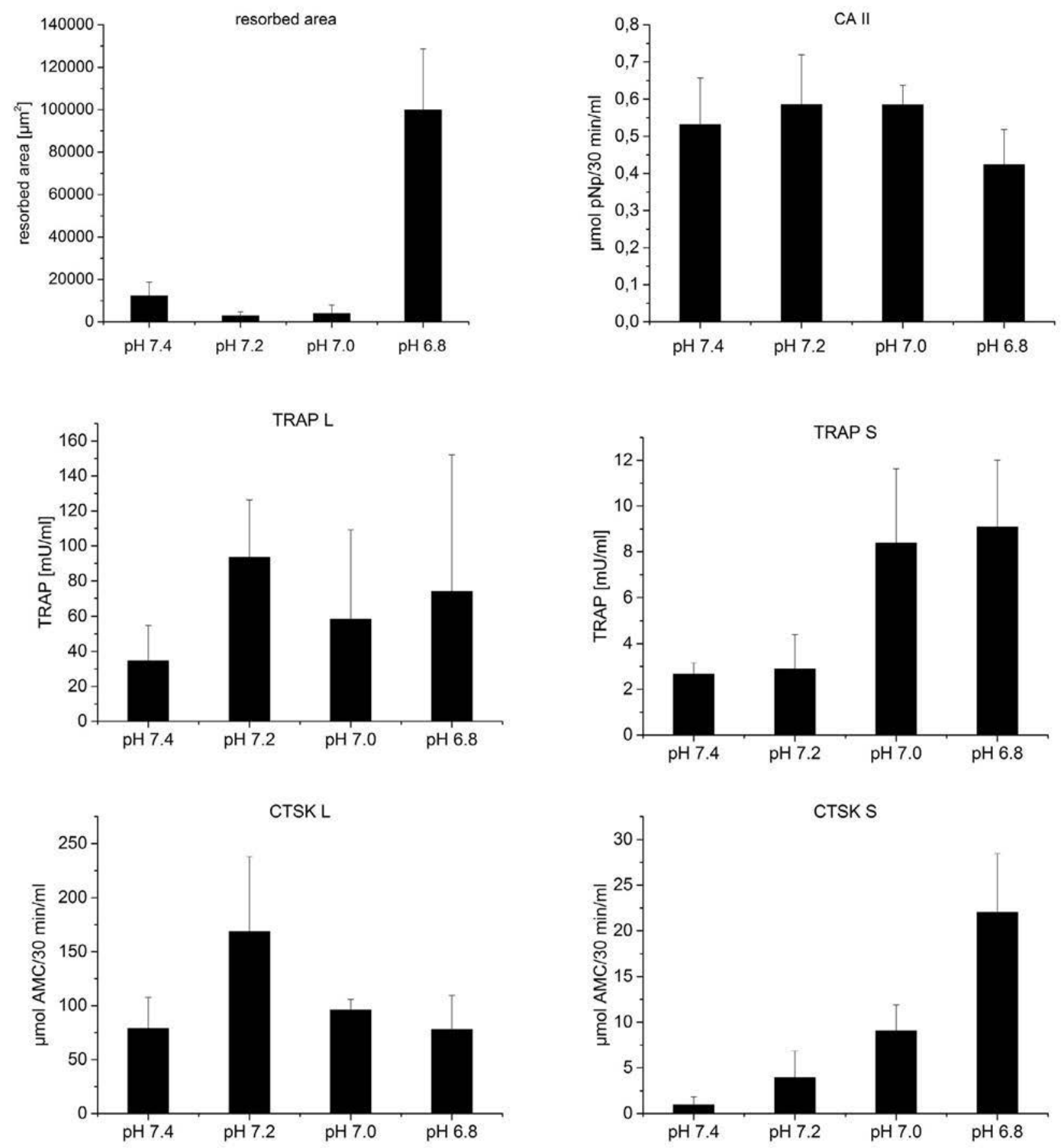

Fig. 6. Resorption of dentin. Resorption pit area and osteoclast related enzyme activities from cell culture supernatants (TRAP S, CTSK S) and lysates (TRAP L, CTSK L, CAII) after $14 \mathrm{~d}$ of PBMC cultivation with osteoclastic stimulation on dentin discs at different $\mathrm{pH}$. Data for cells of three donors (each $n=2$ ) were averaged and shown \pm standard deviation. Two way ANOVA was performed with $\mathrm{pH}$ and donor as parameters. Significant differences $(p<0.05)$ were identified as follows. For resorbed area: $\mathrm{pH} 6.8$ vs. $\mathrm{pH} 7.0, \mathrm{pH} 7.2$ and pH 7.4. For CTSK S: $\mathrm{pH} 6.8$ vs. $\mathrm{pH} 7.0, \mathrm{pH} 7.2$ and pH 7.4 as well as pH 7.0 vs. pH 7.4. For TRAP S: pH 6.8 vs. pH 7.2 and pH 7.4 as well as pH 7.0 vs. pH 7.2 and pH 7.4. For CTSK L: pH 7.2 vs. pH 6.8, pH 7.0 and pH 7.4. Furthermore, significant differences $(p<0.05)$ between two of the three donors were detected for TRAP L, TRAP S and CTSK S activity.

activity and $\mathrm{Ca}^{2+}$, respectively. Correlation between TRAP activity and resorbed area was significant but very low. As expected from the data, there was a good and significant correlation between CTSK, TRAP and $\mathrm{Ca}^{2+}$ (Table 3). For experiments with osteoblast-derived ECM, cells were not lysed to ensure the integrity of the matrix. Therefore, only extracellular enzyme activities were recorded.

\section{Summary of results and comparison between different materials}

The most relevant results of this study are summarised in Table 4. Intracellular TRAP activity and CAII activity correlated with the resorbed area of CPC, while extracellular enzyme activities did not correlate with CPC resorption. Extracellular CTSK activity and extracellular 
$\mathrm{pH} 7.4$
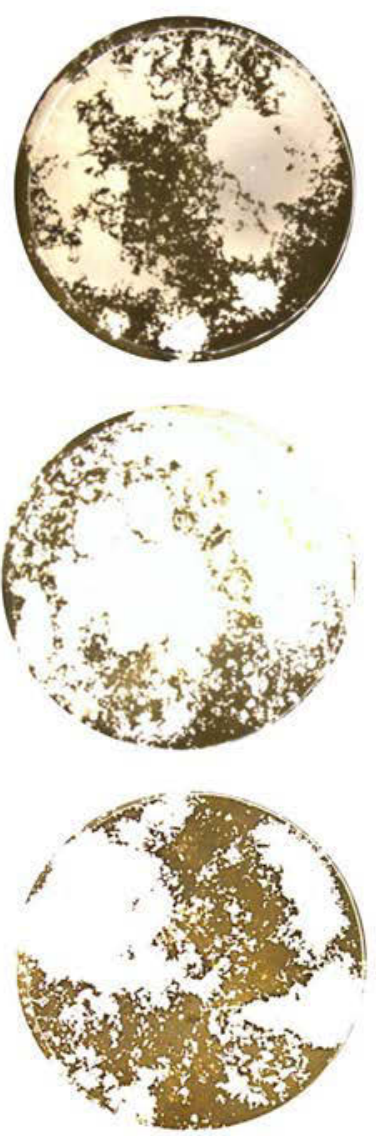

pH 7.2
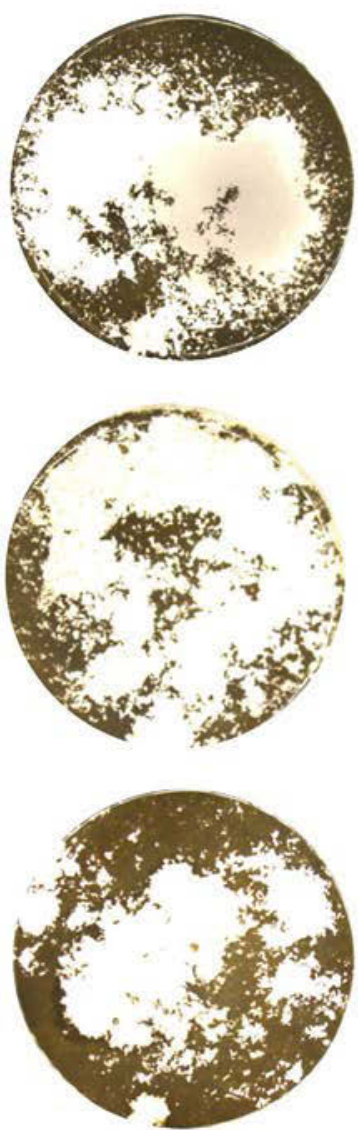

$\mathrm{pH} 7.0$
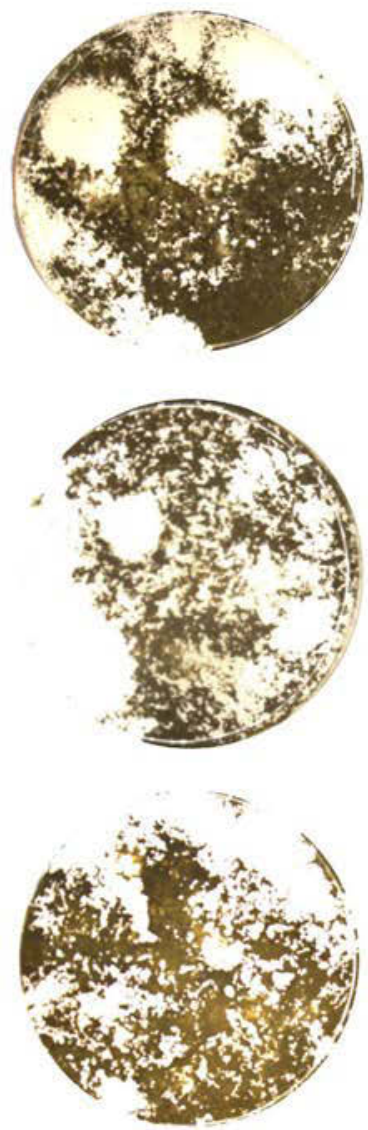

pH 6.8
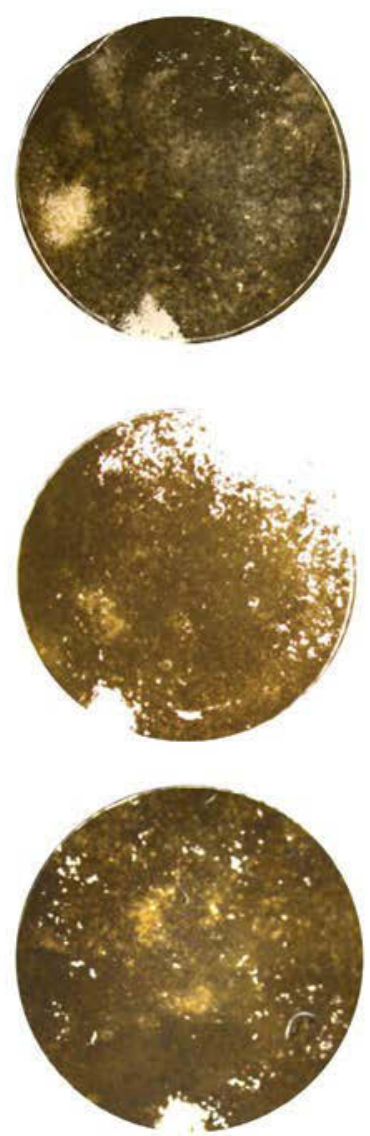

Fig. 7. Representative images of osteoblast-derived ECM after osteoclastic resorption at different $\mathrm{pH}$ shown for cells of three different donors (I, II and IV). Human osteoblasts were cultivated for 4 weeks until a closed layer of mineralised extracellular matrix was formed in the dishes. After removal of the osteoblasts, PBMC were seeded and cultivated for $14 \mathrm{~d}$ under stimulation with M-CSF and RANKL. After fixing with $4 \%$ formaldehyde, von Kossa staining was performed to stain the remaining mineralised matrix after osteoclastic resorption. Images were recorded with a Leica stereomicroscope and represent the whole area of a 48- well dish (12 mm diameter).

TRAP activity correlated with the resorbed area of dentin discs. There was no significant correlation between resorption of osteoblast-derived ECM and extracellular TRAP and CTSK osteoclast specific enzyme activities, but significant correlations between TRAP S and CTSK $\mathrm{S}$, and of both activities to $\mathrm{Ca}^{2+}$ release.

Highest extra- and intracellular TRAP activities were detected on TCPS. Percentage of extracellular TRAP activity, referred to total TRAP activity, was highest on dentin and TCPS and lowest on CPC. TRAP activity varied over a large range, especially the intracellular activity. Highest extracellular TRAP activity was found in osteoclast cultures on osteoblast-derived ECM. CAII activity comprised only a small range. Highest activities were recorded in osteoclast cultures on dentin discs. CTSK activity was analysed in this study, for the first time, to quantify osteoclastogenesis and resorption. Intracellular CTSK activities varied over a broad range and highest values were recorded on dentin. Percentage of extracellular CTSK referred to total CTSK was highest on TCPS and lowest on CPC.

\section{Discussion}

In vitro investigations on cell-mediated resorption of biomaterials are crucial to evaluate the biodegradability of biomaterials and may help to minimise the need for animal experiments during material development as well as to predict the remodelling of resorbable implant materials in clinical applications. However, modern bone graft materials comprise complex structures which are barely accessible by common microscopic methods for the study of osteoclastogenesis and resorption. The idea of the present study was, therefore, to evaluate the correlation between osteoclast-specific enzyme activities and resorption on flat substrates of different chemical composition to find general coherencies which would allow the quantification of osteoclastogenesis and resorption of irregularly structured biomaterials in future.

Different resorbable materials were chosen to cover a broad range of potential application for enzyme activity based resorption tests. Calcium phosphate bone cements represent only the mineral phase of bone and were, 

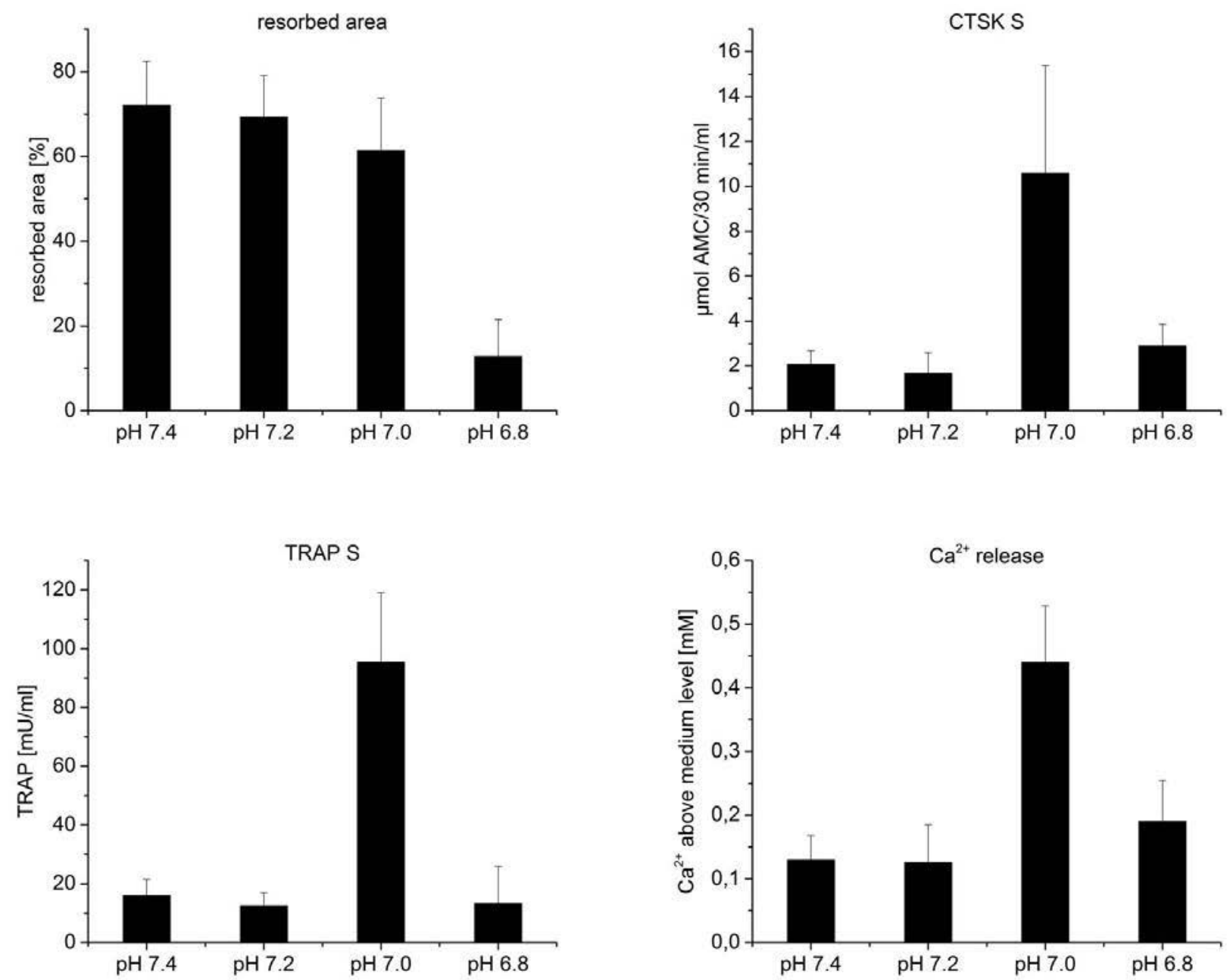

Fig. 8. Resorption of cell derived bone ECM. Resorbed area and osteoclast related enzyme activities from cell culture supernatants and $\mathrm{Ca}^{2+}$ release after $14 \mathrm{~d}$ of PBMC cultivation with osteoclastic stimulation on osteoblast-derived bone $\mathrm{ECM}$ at different $\mathrm{pH}$. Data for cells of three donors (each $n=2)$ were averaged and shown \pm standard deviation. Two way ANOVA was performed with $\mathrm{pH}$ and donor as parameters. Significant differences $(p<0.05)$ were identified as follows. For resorbed area: pH 6.8 vs. pH 7.0, pH 7.2 and pH 7.4 as well as pH 7.0 vs. pH 7.4. For TRAPS: pH 7.0 vs. pH 6.8, pH 7.2 and pH 7.4. For CTSKS: pH 7.0 vs. pH 6.8, pH 7.2 and pH 7.4. For Ca ${ }^{2+}$ release: $\mathrm{pH} 7.0$ vs. $\mathrm{pH}$ 6.8, $\mathrm{pH} 7.2$ and $\mathrm{pH} 7.4$ as well as $\mathrm{pH} 6.8$ vs. pH 7.2. Furthermore, significant differences $(p<0.05)$ between the three donors were detected for TRAPS, resorbed area and $\mathrm{Ca}^{2+}$ release.

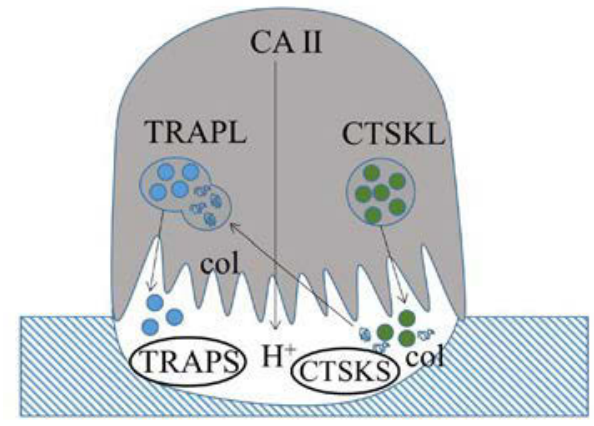

dentin/bone

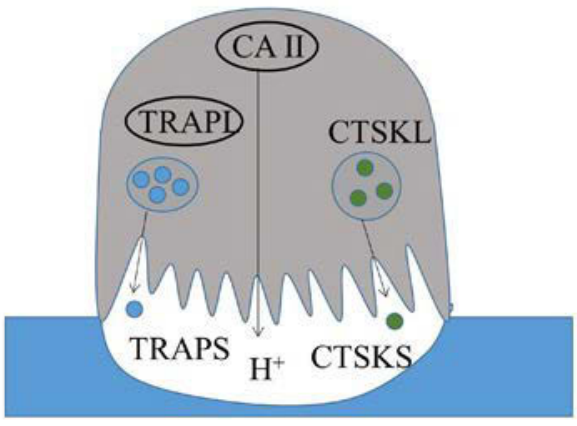

calcium phosphate

Fig. 9. Comparison between osteoclastic resorption of mineralised collagen matrix (dentin, bone) and inorganic calcium phosphate materials. During dentin resorption CTSK degrades the collagenous matrix and the degradation products are further degraded in transcytotic vesicles with TRAP. During resorption of calcium phosphate cement, acidification of the resorption lacuna is sufficient to dissolve the material. Less extracellular CTSK and TRAP were quantified. Resorptive activity towards dentin correlates with extracellular enzyme activities, while resorptive activity towards CPC is correlated to intracellular enzyme activities. Enzyme activities which correlated to resorption are bordered. TRAPS: extracellular TRAP, CTSKS extracellular CTSK, TRAPL intracellular TRAP, CTSKL intracellular CTSK, col degradation products of collagen. 
therefore, used as a model for calcium phosphate based biomaterials. Dentin and osteoblast derived ECM contain both collagen and nanocrystalline hydroxyapatite, but the morphological properties are different.

In this study, the examined enzyme activities were not normalised to the number of multinucleated osteoclasts, since counting of osteoclasts would only be possible on the flat model substrates used in this study and not on irregularly structured materials which are intended to be examined in the application of the resorption assay. We rather aimed to find correlations between resorbed area and enzyme activities without regard to the number of osteoclasts. Numerous in vitro studies with osteoclasts have quantified TRAP activity as a marker for osteoclast development and a correlation between TRAP activity and osteoclast number was reported not only on TCPS, but also on bone (Rissanen et al., 2008), calcium phosphate bone cement (Vahabzadeh et al., 2015) and calcium phosphate ceramics (Davison et al., 2015). It has been suggested that TRAP activity is a measure for osteoclast number rather than osteoclast activity (Alatalo et al., 2000; Rissanen et al., 2008). However, some inconsistency is apparent in studies using TRAP as an osteoclast or even resorption marker: while some studies detected secreted TRAP activity in the cell culture supernatant (Alatalo et al., 2000; Chang et al., 2015; Montazerolghaem et al., 2015; Rissanen et al., 2008), others used cell lysates to analyse the intracellular TRAP activity (Badran et al., 2012; Davison et al., 2015; Vahabzadeh et al., 2015). Only one report analysed the correlation between intra- and extracellular TRAP activity (Kirstein et al., 2006). The authors found, for mouse osteoclasts derived from bone marrow cells on bone slices, a correlation between released TRAP activity and resorption area.

We have also recognised a significant correlation between extracellular TRAP activity and resorbed area for dentin discs, which have a similar composition to bone. In another study (Badran et al., 2012), osteoclasts derived from neonatal rabbit bone cells were cultivated on dentin and three different calcium phosphate ceramics. Highest intracellular TRAP activity was detected with dentin samples, which also showed highest resorbed area. But intracellular TRAP activity was also detected on a nonresorbable hydroxyapatite ceramic and was not different from the TRAP activity on a resorbable biphasic ceramic. Data on extracellular TRAP activity were not provided in this study. Other studies report higher TRAP activity on resorbable compared to non-resorbable materials, but there is no clear evidence that non-resorbing osteoclasts express TRAP to a lower level than resorbing osteoclasts. Comparing the absolute TRAP activity on different substrates, it was obvious in our study that highest intracellular TRAP activities and total TRAP activities were found on the non-resorbable TCPS. On TCPS, the extra- and intracellular TRAP activities show a moderate significant correlation; however, the ratio of secreted TRAP to total TRAP was significantly higher at $\mathrm{pH} 7.0$ compared to all other $\mathrm{pH}$ conditions. These results support the idea of (both intra- and extracellular) TRAP activity as a reliable measure for osteoclast number on TCPS.
A different situation was observed on CPC. Here, a significant correlation between intracellular TRAP activity and resorption was detected. Furthermore, CPC was the material with the lowest percentage of TRAP and CTSK secretion. The different secretion of osteoclast-specific enzymes on calcium phosphate and collagen-containing substrates is illustrated in Fig. 9. Calcium phosphate (as a component of bone matrix or as single component) is necessary to promote actin ring formation in osteoclasts to generate active resorbing osteoclasts (Saltel et al., 2004). When bone, dentin or other mineralised collagen matrices are resorbed, the secretion of CTSK leads to the cleavage of collagen which is further degraded by TRAP in lysosomal vesicles. Possibly, the absence of collagen and collagen degradation products leads to an attenuated secretion of CTSK and TRAP in actively resorbing osteoclasts.

A different situation is found on TCPS, were osteoclasts are in a non-resorbing state, lacking polarisation and actin rings. In this case the secretion of TRAP and CTSK might be regulated by other factors. TRAP activities of osteoclasts on CPC have been reported in previous studies to be higher than on TCPS (Oh et al., 2010) and lower than on bone (Montazerolghaem et al., 2015). However, in both studies the resorption of the cements was not checked.

Considering our data, the comparison between collagencontaining and pure mineral containing materials based on osteoclastic enzyme activities must be judged critically and is not recommended. However, from our results, there is evidence that intracellular TRAP activity might be a good indicator for resorption of CPC and possibly other calcium phosphate containing biomaterials. These results are partly supported by other studies (Chang et al., 2015), analysing extracellular TRAP activity and resorption of RAW 264.7 osteoclast-like cells on calcium phosphate coated surfaces in the presence of different calcium phosphate ceramic particles. While TRAP activity was highest in the presence of hydroxyapatite particles, resorbed area was highest in the presence of calcium pyrophosphate dehydrate (CPPD) particles, which suggests no correlation between extracellular TRAP activity and resorption of calcium phosphate (Chang et al., 2015). Mc Millan and co-workers (MacMillan et al., 2014) reported a coherence between intracellular TRAP activity and resorbed area for rat bone marrow derived osteoclasts on bone and different nano- and microcrystalline ceramic materials.

CAII plays an important role in the resorptive activity of osteoclasts (Lehenkari et al., 1998) and its gene expression is well accepted as an osteoclast marker. However, only few studies have used CAII activity, instead of its mRNA expression, to analyse osteoclast formation and activity (Bernhardt et al., 2015; Detsch et al., 2010; Detsch and Boccaccini, 2015; Schumacher et al., 2016). The present study is the first to correlate CAII activity with osteoclastic resorption. A moderate correlation between CAII activity and resorption was only detected on $\mathrm{CPC}$, while on the other examined materials no correlation existed between CAII activity and resorption activity. We therefore suggest that CAII is not abundantly suitable as resorption marker. Furthermore, the range between low and high CAII activity is very small, which can lead to misinterpretation of 
data. Since CAII activity reflected only the resorption of $\mathrm{CPC}$, the measurement of CAII is merely recommended for investigations on CPC and possibly other calcium phosphate based materials, preferably in combination with TRAP activity measurement.

CTSK is a highly specialised protease, which is capable of degrading collagen I molecules within the helical regions (Novinec and Lenarčič, 2013). Its mRNA expression belongs to the most frequently analysed osteoclast markers. Some studies also investigated the CTSK protein expression using Western blot analysis (Manrique et al., 2016; Zhang et al., 2015) or ELISA (Sun et al., 2013). Nevertheless, evidence for a correlation between CTSK expression and resorption has not yet provided. A cytochemical assay on bone sections demonstrated that the active form of CTSK is already formed intracellularly and that CTSK is secreted in its active form (Dodds, 2003). In the present study, a fluorogenic CTSK substrate was probed both with cell lysates and cell culture supernatants to explore possible correlations between the enzyme activity and resorbed area of the substrates. CTSK activity could be detected both extra- and intracellularly on the different materials. There was a significant correlation between extracellular CTSK activity and resorbed area on dentin and significant correlations between extracellular CTSK activity and both $\mathrm{Ca}^{2+}$ release and extracellular TRAP activity in cultures with osteoblast derived ECM. However, in the latter experiment with ECM, no correlation of CTSK, TRAP and $\mathrm{Ca}^{2+}$ with the resorbed area was found. One possible explanation could be the limited availability of resorbable material in this special assay. As evident in Fig. 8, around $60-80 \%$ of the mineralised matrix is already resorbed at $\mathrm{pH}$ 7.4, 7.2 and 7.0. Therefore, a possible higher resorption activity at $\mathrm{pH} 7.0$, as implicated by the enzyme activities, could be hampered by lacking availability of resorbable substrate. Taken together, we suggest the determination of extracellular CTSK activity as a resorption marker for dentin and other materials containing mineralised collagen. Fluorimetric measurement of CTSK activity is far less expensive compared to ELISA investigations and less time consuming compared to immunoblotting. The presence of CTSK activity does not necessarily imply resorptive activity, as shown on TCPS with very high CTSK secretion. However, extracellular CTSK activity showed coherencies with the number of TRAP positive osteoclasts on nonresorbable TCPS. Osteoclasts on materials which do not contain collagen, like CPC and possibly other resorbable calcium phosphate materials, did not show a correlation between CTSK activity and resorptive activity.

Extracellular $\mathrm{Ca}^{2+}$ concentration is also suggested as a marker for osteoclastic resorption. This is reasonable for materials like bone and dentin, which do not support the crystallisation of calcium phosphate from the cell culture medium. On CPC and bioactive calcium phosphate ceramics, the analysis of $\mathrm{Ca}^{2+}$ release by osteoclastic resorption seems to be questionable, since elevated $\mathrm{Ca}^{2+}$ levels caused by osteoclastic resorption could be levelled by enhanced crystallisation. Resorption of osteoblast derived ECM led to an increase of $\mathrm{Ca}^{2+}$ concentration above medium level and the additional $\mathrm{Ca}^{2+}$ amount was in good correlation to extracellular TRAP and CTSK activities.
It has been demonstrated that slightly acidic $\mathrm{pH}$ conditions (6.8-7.2) favour osteoclast resorption activity (Arnett and Dempster, 1986) as well as osteoclast formation (Schilling et al., 2004). In the present study, we exploited this phenomenon to generate samples with different osteoclast numbers and possibly resorption activity to get robust data for the correlation with the osteoclast specific enzyme activities. Interestingly, as a side effect, we found different $\mathrm{pH}$ optimal for the resorption of the different examined materials. While CPC samples showed the highest resorption around $\mathrm{pH}$ 7.2, resorption of dentin was maximal at $\mathrm{pH} 6.8$ and maximum resorbed area of osteoblast derived ECM was detected around $\mathrm{pH} 7.4$ (but maximal $\mathrm{Ca}^{2+}$ release and TRAP/CTSK activity was detected at $\mathrm{pH}$ 7.0). Furthermore, since different materials influence the $\mathrm{pH}$ of the cell culture medium (as also shown in our study where CPC samples acidified the cell culture medium in contrast to the other examined materials), comparative resorption measurements of different materials should be ideally performed at different $\mathrm{pH}$.

\section{Conclusions}

The correlation between osteoclast-specific enzyme activities and resorption is strongly dependent on the resorbed material. For osteoclasts on CPC, significant correlations between intracellular TRAP activity and, to a lesser extend, intracellular CAII activity with resorption were recorded: osteoclasts on dentin displayed a significant correlation between extracellular TRAP and CTSK activity and resorption. The ratio between intra- and extracellular TRAP and CTSK activities depends on the resorbed material, on the donor of the primary cells and in some cases on the $\mathrm{pH}$. It can be concluded for future in vitro resorption investigations that the measurement of resorption using osteoclast specific enzyme activities can only be successful when the appropriate enzyme activities for the respective material are chosen and influence from other experimental conditions like $\mathrm{pH}$ are considered. In this context special attention should be paid on the different acidification potential of biomaterials since it can strongly influence osteoclast activity.

\section{Acknowledgements}

The authors thank Corina Vater for providing canine teeth of minipigs and Diana Jünger for preparing dentin discs. We acknowledge financial support by DFG (SFB TR79/ M2 and BE 5139/3-1). We wish to confirm that there are no known conflicts of interest associated with this publication and there has been no significant financial support for this work that could have influenced its outcome.

\section{References}

Alatalo SL, Halleen JM, Hentunen TA, Mönkkönen J, Väänänen HK (2000) Rapid screening method for osteoclast differentiation in vitro that measures tartrate- 
resistant acid phosphatase 5b activity secreted into the culture medium. Clin Chem 46: 1751-1754.

Arnett TR, Dempster DW (1986) Effect of pH on bone resorption by rat osteoclasts in vitro. Endocrinology 119: 119-124.

Badran Z, Pilet P, Verron E, Bouler J-M, Weiss P, Grimandi G, Guicheux J, Soueidan A (2012) Assay of in vitro osteoclast activity on dentine, and synthetic calcium phosphate bone substitutes. J Mater Sci Mater Med 23: 797-803.

Bernhardt A, Schumacher M, Gelinsky M (2015) Formation of osteoclasts on calcium phosphate bone cements and polystyrene depends on monocyte isolation conditions. Tissue Eng Part C Methods 21: 160-170.

Chang C-C, Tsai Y-H, Liu Y, Lin S-Y, Liang Y-C (2015) Calcium-containing crystals enhance receptor activator of nuclear factor $\kappa \mathrm{B}$ ligand/macrophage colony-stimulating factor-mediated osteoclastogenesis via extracellularsignal-regulated kinase and p38 pathways. Rheumatology (Oxford) 54: 1913-1922.

Christgau S, Rosenquist C, Alexandersen P, Bjarnason NH, Ravn P, Fledelius C, Herling C, Qvist P, Christiansen C (1998) Clinical evaluation of the Serum CrossLaps One Step ELISA, a new assay measuring the serum concentration of bone-derived degradation products of type I collagen C-telopeptides. Clin Chem 44: 2290-2300.

Davison NL, Su J, Yuan H, van den Beucken JJJP, de Bruijn JD, Barrère-de Groot F (2015) Influence of surface microstructure and chemistry on osteoinduction and osteoclastogenesis by biphasic calcium phosphate discs. Eur Cell Mater 29: 314-329.

Detsch R, Hagmeyer D, Neumann M, Schaefer S, Vortkamp A, Wuelling M, Ziegler G, Epple M (2010) The resorption of nanocrystalline calcium phosphates by osteoclast-like cells. Acta Biomater 6: 3223-3233.

Detsch R, Boccaccini AR (2015) The role of osteoclasts in bone tissue engineering. J Tissue Eng Regen Med 9: 1133-1149.

Detsch R, Schaefer S, Deisinger U, Ziegler G, Seitz H, Leukers B (2011) In vitro: osteoclastic activity studies on surfaces of $3 \mathrm{D}$ printed calcium phosphate scaffolds. $\mathrm{J}$ Biomater Appl 26: 359-380.

Dodds RA (2003) A cytochemical assay for osteoclast cathepsin K activity. Cell Biochem Funct 21: 231-234.

Glenske K, Wagner A-S, Hanke T, Cavalcanti-Adam EA, Heinemann S, Heinemann C, Kruppke B, Arnhold S, Moritz A, Schwab EH, Worch H, Wenisch S (2014) Bioactivity of xerogels as modulators of osteoclastogenesis mediated by connexin 43. Biomaterials 35: 1487-1495.

Grossardt C, Ewald A, Grover LM, Barralet JE, Gbureck U (2010) Passive and active in vitro resorption of calcium and magnesium phosphate cements by osteoclastic cells. Tissue Eng Part A 16: 3687-3695.

Halleen JM, Alatalo SL, Janckila AJ, Woitge HW, Seibel MJ, Väänänen HK (2001) Serum tartrate-resistant acid phosphatase $5 \mathrm{~b}$ is a specific and sensitive marker of bone resorption. Clin Chem 47: 597-600.

Halleen JM, Räisänen S, Salo JJ, Reddy SV, Roodman GD, Hentunen TA, Lehenkari PP, Kaija H, Vihko P, Väänänen HK (1999) Intracellular fragmentation of bone resorption products by reactive oxygen species generated by osteoclastic tartrate-resistant acid phosphatase. J Biol Chem 274: 22907-22910.

Halleen JM, Tiitinen SL, Ylipahkala H, Fagerlund KM, Väänänen HK (2006) Tartrate-resistant acid phosphatase $5 b$ (TRACP 5b) as a marker of bone resorption. Clin Lab 52: 499-509.

Hayman AR, Cox TM (2003) Tartrate-resistant acid phosphatase knockout mice. J Bone Miner Res 18: 19051907.

Hefti T, Frischherz M, Spencer ND, Hall H, Schlottig F (2010) A comparison of osteoclast resorption pits on bone with titanium and zirconia surfaces. Biomaterials 31: 7321-7331.

Innocenti A, Scozzafava A, Parkkila S, Puccetti L, De Simone G, Supuran CT (2008) Investigations of the esterase, phosphatase, and sulfatase activities of the cytosolic mammalian carbonic anhydrase isoforms I, II, and XIII with 4-nitrophenyl esters as substrates. Bioorg Med Chem Lett 18: 2267-2271.

Kirstein B, Chambers TJ, Fuller K (2006) Secretion of tartrate-resistant acid phosphatase by osteoclasts correlates with resorptive behavior. J Cell Biochem 98: 1085-1094.

Lehenkari P, Hentunen TA, Laitala-Leinonen T, Tuukkanen J, Väänänen HK (1998) Carbonic anhydrase II plays a major role in osteoclast differentiation and bone resorption by effecting the steady state intracellular $\mathrm{pH}$ and $\mathrm{Ca}^{2+}$. Exp Cell Res 242: 128-137.

Long T, Hong F, Shen S, Wang L, Wang Y, Wang J (2012) In vitro degradation of electrodeposited calcium phosphate coatings by osteoclast-like cells. Biomed Mater Bristol Engl 7: 45012.

Lutter A-H, Hempel U, Wolf-Brandstetter C, Garbe AI, Goettsch C, Hofbauer LC, Jessberger R, Dieter P (2010) A novel resorption assay for osteoclast functionality based on an osteoblast-derived native extracellular matrix. J Cell Biochem 109: 1025-1032.

MacMillan AK, Lamberti FV, Moulton JN, Geilich BM, Webster TJ (2014) Similar healthy osteoclast and osteoblast activity on nanocrystalline hydroxyapatite and nanoparticles of tri-calcium phosphate compared to natural bone. Int J Nanomedicine 9: 5627-5637.

Manrique E, Castillo LM, Lazala O, Guerrero CA, Acosta O (2016) Bone resorptive activity of human peripheral blood mononuclear cells after fusion with polyethylene glycol. J Bone Miner Metab DOI:10.1007/ s00774-016-0744-0.

Minkin C (1982) Bone acid phosphatase: Tartrateresistant acid phosphatase as a marker of osteoclast function. Calcif Tissue Int 34: 285-290.

Montazerolghaem M, Karlsson Ott M, Engqvist H, Melhus H, Rasmusson AJ (2015) Resorption of monetite calcium phosphate cement by mouse bone marrow derived osteoclasts. Mater Sci Eng C Mater Biol Appl 52: 212-218.

Neutzsky-Wulff AV, Sørensen MG, Kocijancic D, Leeming DJ, Dziegiel MH, Karsdal MA, Henriksen K (2010) Alterations in osteoclast function and phenotype induced by different inhibitors of bone resorptionimplications for osteoclast quality. BMC Musculoskelet Disord 11: 109. 
Novinec M, Lenarčič B (2013) Cathepsin K: a unique collagenolytic cysteine peptidase. Biol Chem 394: 11631179.

Oh S-A, Lee G-S, Park J-H, Kim H-W (2010) Osteoclastic cell behaviors affected by the $\alpha$-tricalcium phosphate based bone cements. J Mater Sci Mater Med 21: 3019-3027.

Reichert C, Götz W, Reimann S, Keilig L, Hagner M, Bourauel C, Jäger A (2013) Resorption behavior of a nanostructured bone substitute: in vitro investigation and clinical application. J Orofac Orthop 74: 165-174.

Rissanen JP, Suominen MI, Peng Z, Halleen JM (2008) Secreted tartrate-resistant acid phosphatase $5 \mathrm{~b}$ is a Marker of osteoclast number in human osteoclast cultures and the rat ovariectomy model. Calcif Tissue Int 82: 108-115.

Saltel F, Destaing O, Bard F, Eichert D, Jurdic P (2004) Apatite-mediated actin dynamics in resorbing osteoclasts. Mol Biol Cell 15: 5231-5241.

Schilling AF, Linhart W, Filke S, Gebauer M, Schinke T, Rueger JM, Amling M (2004) Resorbability of bone substitute biomaterials by human osteoclasts. Biomaterials 25: 3963-3972.

Schindelin J, Arganda-Carreras I, Frise E, Kaynig V, Longair M, Pietzsch T, Preibisch S, Rueden C, Saalfeld S, Schmid B, Tinevez J-Y, White DJ, Hartenstein V, Eliceiri K, Tomancak P, Cardona A (2012) Fiji: an open-source platform for biological-image analysis. Nat Methods 9: 676-682.

Schumacher M, Henß A, Rohnke M, Gelinsky M (2013) A novel and easy-to-prepare strontium(II) modified calcium phosphate bone cement with enhanced mechanical properties. Acta Biomater 9: 7536-7544.

Schumacher M, Wagner AS, Kokesch-Himmelreich J, Bernhardt A, Rohnke M, Wenisch S, Gelinsky M (2016) Strontium substitution in apatitic CaP cements effectively attenuates osteoclastic resorption but does not inhibit osteoclastogenesis. Acta Biomater 37: 184194. Soysa NS, Alles N, Aoki K, Ohya K (2009) Three-dimensional characterization of osteoclast boneresorbing activity in the resorption lacunae. J Med Dent Sci 56: 107-112.

Sun S, Karsdal MA, Bay-Jensen AC, Sørensen MG, Zheng Q, Dziegiel MH, Maksymowych WP, Henriksen K (2013) The development and characterization of an ELISA specifically detecting the active form of cathepsin K Clin Biochem 46: 1601-1606. Vahabzadeh S, Roy M, Bose S (2015) Effects of silicon on osteoclast cell mediated degradation, in vivo osteogenesis and vasculogenesis of brushite cement. J Mater Chem B Mater Biol Med 3: 89738982.

Winkler T, Hoenig E, Gildenhaar R, Berger G, Fritsch D, Janssen R, Morlock MM, Schilling AF (2010) Volumetric analysis of osteoclastic bioresorption of calcium phosphate ceramics with different solubilities. Acta Biomater 6: 4127-4135.

Zhang Y, Lin Y, Xiao L, Feng E, Wang W, Lin L (2015) The effects of icariine concentration on osteoclasts bone resorption induced by titanium particles in vitro. Regen Biomater 2: 197-202.
Zhang Z, Egaña JT, Reckhenrich AK, Schenck TL, Lohmeyer JA, Schantz JT, Machens H-G, Schilling AF (2012) Cell-based resorption assays for bone graft substitutes. Acta Biomater 8: 13-19.

\section{Discussion with Reviewers}

João Costa-Rodrigues: Since TRAP is expressed by other cell types rather than osteoclasts, like, for example, some classes of leukocytes, authors should normalise the values obtained for TRAP activity according to the number of osteoclastic cells in PBMC cultures. The same thing applies for CAII and CTSK quantification.

Authors: TRAP exists in different isoforms. Osteoclasts were shown to express TRAP5b isoform, which can be detected with a specific fluorometric assay as proposed by Janckila et al. (2001) and applied in this study. TRAP5a activity which is expressed by other cells like macrophages is not detected with this assay.

João Costa-Rodrigues: Authors should discuss about the intracellular mechanisms that might be involved in the apparent ability of osteoclasts to "sense" the kind of substrate that they have to resorb. Furthermore, authors should also discuss about the physiological relevance of the present findings: is it possible that in vivo osteoclasts are able to recognise different mineral contents of bone tissue? Authors: The recognition of different substrates by osteoclasts is triggered by $\alpha \mathrm{v} \beta 3$ integrins (Faccio et al., 2003; Fuller et al., 2010). However, the differences in osteoclast enzyme secretion, which were detected in our study, are not necessarily caused by different signalling. It might rather be explained by the resorption process itself. During resorption of collagen-containing substrates, CTSK derived cleavage products of collagen are further degraded by TRAP in lysosomal vesicles and exocytosed. This could cause the elevated extracellular TRAP and CTSK activity. During the resorption of pure calcium phosphate materials no collagen degradation will occur and therefore no enhanced TRAP secretion would be triggered.

\section{Additional References}

Faccio R, Novack DV, Zallone A, Ross FP, Teitelbaum SL (2003) Dynamic changes in the osteoclast cytoskeleton in response to growth factors and cell attachment are controlled by beta3 integrin. J Cell Biol 4: 499-509.

Fuller K, Ross JL, Szewczyk KA, Moss R, Chambers TJ (2010) Bone is not essential for osteoclast activation. PloS One. 17: pii: e12837.

Janckila AJ, Takahashi K, Sun SZ, Yam LT (2001) Naphthol-ASBI phosphate as a preferred substrate for tartrate-resistant acid phosphatase isoform 5b. J Bone Miner Res 16: 788-93.

Editor's note: The Scientific Editor responsible for this paper was Christine Hartmann. 